\title{
Enhancement of Polyolefins Compatibility with Natural Fibers Through Chemical Modification
}

\author{
Magdy Y. Abdelaal ${ }^{1}$, Elsayed H. Elmossalamy ${ }^{2, *}$, Saleh O. S. Bahaffi ${ }^{3}$ \\ ${ }^{1}$ Chemistry Department, Faculty of Science, Mansoura University, Mansoura, ET-35516, Egypt \\ ${ }^{2}$ Chemistry Department, Faculty of Science, Benha University, Benha, Egypt \\ ${ }^{3}$ Chemistry Department, Faculty of Science, king Abdulaziz University, PO Box 80203, Jeddah 21589, Saudi Arabia
}

\begin{abstract}
In the current study, polyethylene (PE) was used as representative example of polyolefins and has been chemically modify through grafting with maleic anhydride. Conditions of the chemical modification process have been adjusted to obtain higher grafting yield with maleic anhydride and the obtained product has been characterized with conventional techniques such as FT-IR spectroscopy as well as with some chemical tests. A suitable amount of saw dust as representative example of natural fibers has been collected and prepared in the normal way to be suitable for casting with PE to attain Wood Plastic Composite (WPC). The obtained materials have been tested regarding their some mechanical, physical and chemical characteristics.
\end{abstract}

Keywords Modification, Natural Fiber, Grafting, Polyolefins, Wood, Tensile Strength

\section{Introduction}

Composites are materials consisting of two or more identifiable constituents but not mixed to an atomic scale[1] and are controlled by the properties of their individual compositions and their interaction. The major constituents of wood - plastic composites (WPC) are the fillers either wood or generally natural fibers and the matrix which can be thermosetting or thermoplastics resins in addition to other chemical additives.

The use of fillers in thermoplastic industry is a common way to increase stiffness and strength to plastics. Inorganic fillers are of the greatest in demand especially calcium carbonate, glass fiber, clay, talc and mica. The supposed environmentally friendly nature of organic fillers has attracted the industry and has led to a major shift in choosing filler types. The growth of WPCs has shown a jump during the last two decades in the plastic industry and the acceptance of WPC which are currently used in various applications such as decking, roof tiles, siding, window and door frames attracted the attention of industry to the organic fillers[2].

Numerous studies over the past decades on wood fiber plastic composites indicated that composites can be readily formed using compounding and compression molding are normally made by mixing wood fiber with polymer, or by adding wood fiber as filler in a polymer matrix and pressing

* Corresponding author:

sbdmina@yahoo.com (Elsayed H. Elmossalamy)

Published online at http://journal.sapub.org/ajps

Copyright (C) 2012 Scientific \& Academic Publishing. All Rights Reserved or molding it under high pressure and temperature. Although different compounding techniques can be applied to produce WPCs, twin screw extruder is still the standard in the industry resulting in production of composites having a high modulus and a low rate of water absorption although there is no much investigation to understand the effect of process variables of a twin screw extrusion on characteristics of WPCs[4].

WPC covers a wide range of composite materials using plastics such as polypropylene (PP), polyvinylchloride (PVC) and polyethylene (PE) and binders/fillers such as wood flour, flax fibers and other natural fibers[5]. The first generation of WPC was a combination of recycled wood flour or chips and binders. Unfortunately, such composites products were ideal for relatively less demanding applications. Recently, there has been an increased interest in the production of WPCs in order to find a viable alternate use for residual plant fiber material and thermoplastics[6-12].

The new generations of WPCs exhibits superior mechanical properties, high dimensional stability help to produce complex shapes. They are tough, stable and can be extruded to high dimensional tolerances[13]. The new WPC materials are high-end technology products for demanding engineered applications[2]. Mixing wood flour with plastic produces the most common type of the WPCs. The advantage of WPCs is their processing ability just like a plastic with the best features of wood and plastics. Next are the main advantages of WPCs:

- They are true hybrid materials which combine the best properties of wood and plastics.

- Wide range and low cost raw materials can be used in the production. Wastes of wood recycled plastics become 
resources by converting them into WPC instead of causing environmental concerns.

- They are competitive even in price with conventional materials such as timber, medium density fiberboard (MDF) and PVC.

- They can be produced and fabricated easier than using traditional wood processing techniques.

- They are available in a broad range of finishes and appearances.

Wood is a lignocellulosic material composed mainly of cellulose (50-65\%), reasonable content of lignin $(20-25 \%)$ in addition to some extractives and traces of ash (1-10\%). The ratio of constituents differs based on species of wood[14].

Application of lignocellulosics as fillers and reinforcements in thermoplastics found acceptance in commodity plastics applications in the past few years. There are several resources for the lignocellulosics used in the reinforcement of thermoplastics. They can be obtained from both forestry and agricultural resources. The physical form can vary from fine powders such as in wood flour to fibers including but not limited to kenaf, flax, sisal and other agro-based materials. The cost and performance of the final composite products dictates the type of lignocelluloses to be used in the plastics. Literature also cites the use of typical plastics such as polyethylene, polypropylene, polyvinyl chloride and also some elastomeric co-polymers for blending with the lignocelluloses. The manufacturing temperature and variety of applications in industry of blends are influenced by the thermal characteristics of the wood flour and the biodegradable polymer involved[8].

Despite the advantages of WPC over wood and plastic, the interaction between wood and plastic at fiber-matrix interface does not necessarily yield strong bonds[15]. The major reason for weak bonds has been attributed to the polar nature of the wood (hydroxyl groups) while some plastics such as PE and PP are non-polar polymers [16].

To develop composites with superior bonds at the interface, it is necessary to modify the wood fiber by chemical reaction with a suitable coupling agents or coating the fiber with appropriate resins/chemicals. Such surface modifications of the wood fiber would improve the interfacial bond strength, which is a critical factor for obtaining better mechanical properties of composites[17]. The other alternative is to modify the plastic component in the WPC either by using blends with different plastic types or by using coupling agent which may be compatible with the hydrophobic plastic components and the hydrophilic wood or natural fiber component. In such cases grafted polypropylene and/or polyethylene with maleic anhydride can be of benefits in this regard[18-19].

\section{Experimental Part}

\subsection{Materials and Techniques}

All chemicals are purchased by Aldrich unless otherwise mentioned. Thermal and FT-IR Spectroscopic analyses used for characterization of PE-g-MAH were achieved in the department. Tensile testing has been also performed in the Faculty of Engineering, KAU at Saudi Arabia.

\subsection{Grafting of maleic anhydride (MAH) onto PE}

A mixture of $70 \mathrm{~g}$ of PE (2.5 mole), $49 \mathrm{~g}$ of Maleic anhydride ( 0.5 mole) and $1.2 \mathrm{~g}$ of benzoylperoxide ( $5 \mathrm{mmole})$ was added to $250 \mathrm{ml}$ of benzene in $500 \mathrm{ml}$ round bottom flask fitted with reflux condenser and magnetic stirrer. The mixture was stirred with star magnet while reflux for $2 \mathrm{~h}$ and then left to cool while stirring until the temperature reduced to $60^{\circ} \mathrm{C}$. The reaction mixture has been poured onto a large amount of ethanol while stirring. The obtained product has been collected by filtration, air dried at $50{ }^{\circ} \mathrm{C}$ under reduced pressure and prepared for characterization by using FT-IR spectroscopic analysis.

\subsection{Sample Preparation}

Saw dust (SD) used as reinforcing material was a mixture of different wood species collected from public carpentries in Jeddah, Saudi Arabia. The particle sizes of the filler were 80-100 mesh. Commercial PE produced by the Saudi Basic Industrial Corp. (SABIC), Saudi Arabia was converted into small particles. A maleated PE (MAPE) used as the coupling agent in this study was prepared in the laboratory through grafting of maleic anhydride onto PE as mentioned above.

\subsection{Compounding}

The saw dust was dried at $40^{\circ} \mathrm{C}$ under reduced pressure for $24 \mathrm{~h}$ to moisture content of about $2 \%$ and then stored in sealed polyethylene bags until needed. The laboratory size extruder was a twin-screw type which blends thermoplastic composites reinforced with saw dust through melt blending, extrusion and palletizing. The blending temperature required to prevent degradation of the saw dust was $120^{\circ} \mathrm{C}$. The resulting pellets were dried at $80^{\circ} \mathrm{C}$ for $24 \mathrm{~h}$ before being melt press molded into test specimens. All samples were melt press molded using a melt press of $10 \mathrm{kN} / \mathrm{cm}^{2}$.

Saw dust ratio was up to $45 \%$ based on the total weight of saw dust and PE prior to compounding as shown in Table 1. Content of PE-g-MAH, which was used as a coupling agent, was $5.0 \%$ based on the total weight of PE and saw dust.

Table 1. Composition (\%) of the PE-Saw dust blends

\begin{tabular}{|c|c|c|c|c|c|}
\hline PE & 100 & 95 & 85 & 75 & 55 \\
\hline Saw Dust & 0 & 5 & 15 & 25 & 45 \\
\hline PE-g-MAH & 5 & 5 & 5 & 5 & 5 \\
\hline
\end{tabular}

\subsection{FT-IR Spectroscopic Analysis}

Samples of polyethylene (PE), maleic anhydride (MAH) and polyethylene grafted with maleic anhydride (PE-g-MAH) have been characterized by using FT-IR Spectroscopic 
analysis. The spectra of the above mentioned samples are shown in Figures 1-3.

\subsection{Thermal Analysis}

Samples of polyethylene, saw dust and wood plastic composite (WPC) have been characterized by using thermo-gravimetric analysis (DTG) in air and with heating rate of $10^{\circ} \mathrm{C} / \mathrm{min}$. Results are represented in Figures 4-6.

\subsection{Tensile Strength Measurements}

Single tensile tests for PE-SD WPC were conducted to measure the tensile strengths with a Universal Testing Machine at the Faculty of Engineering, King Abdulaziz University, Saudi Arabia. Test specimens for the evaluation of tensile strength were molded in a mold suitable to produces samples with the dimensions of $\mathrm{W}=19 \mathrm{~mm}, \mathrm{~L}=$ $115 \mathrm{~mm}$ and $\mathrm{T}=3.5 \mathrm{~mm}$. The tests were conducted on samples at a speed of $100 \mathrm{~mm} / \mathrm{min}$ and were repeated 5 times for each condition to obtain more representative results shown in Table 2.

Table 2. Tensile properties WPC samples with and without PE-g-MAH

\begin{tabular}{|c|c|c|c|c|}
\hline \multirow{2}{*}{$\begin{array}{c}\text { Saw Dust } \\
(\%)\end{array}$} & \multicolumn{2}{|c|}{ 0\% PE-g-MAH } & \multicolumn{2}{c|}{ 5\% PE-g-MAH } \\
\cline { 2 - 5 } & TS* & TM$^{*}$ & TS* & TM$^{*}$ \\
\hline 0 & 38.02 & 45.44 & N/A & N/A \\
\hline 5 & 37.45 & 44.28 & 40.70 & 44.22 \\
\hline 15 & 36.90 & 41.08 & 44.10 & 46.64 \\
\hline 25 & 36.48 & 38.16 & 48.34 & 46.18 \\
\hline 45 & 34.32 & 31.64 & 52.06 & 43.92 \\
\hline
\end{tabular}

TS $=$ Tensile Strength; and TM $=$ Tensile Modulus

\section{Results and Discussion}

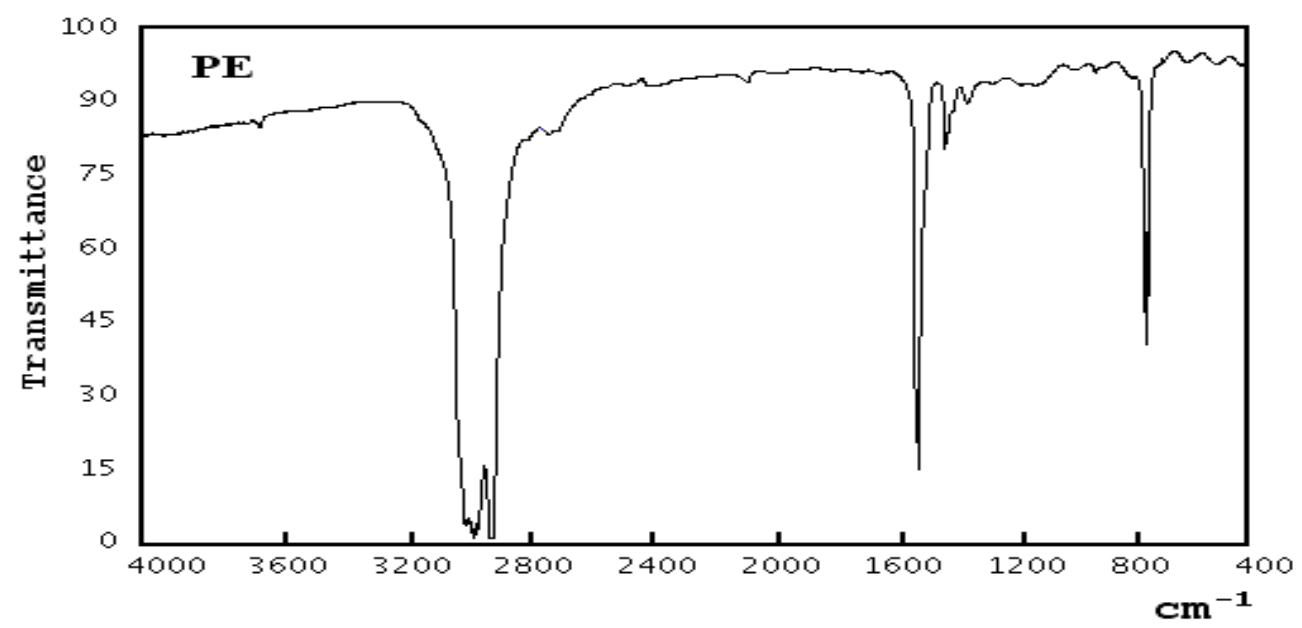

Figure 1. FT-IR Spectrum of PE 


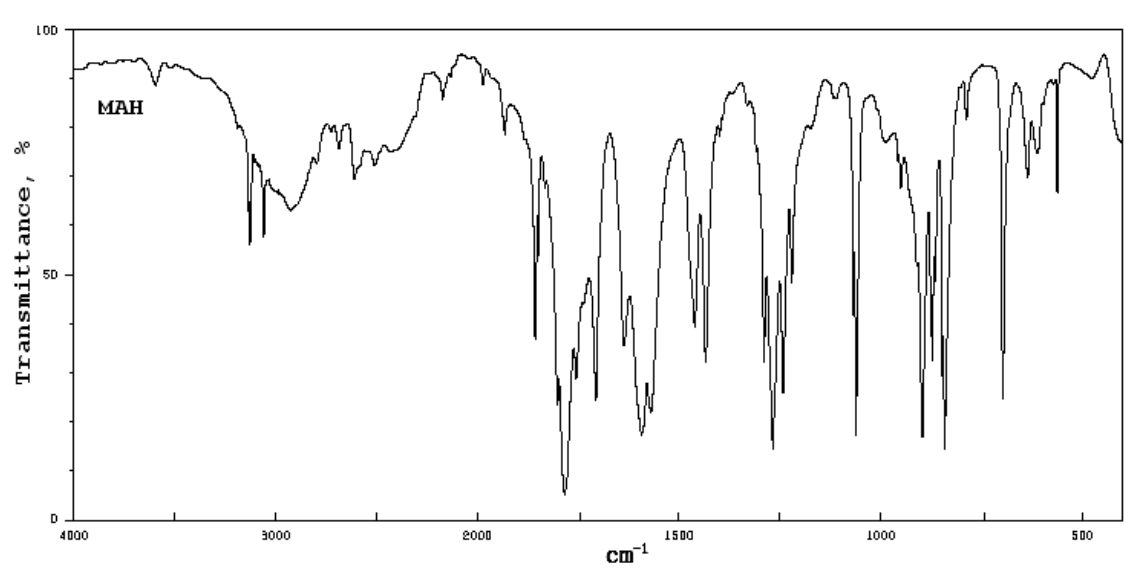

Figure 2. FT-IR Spectrum of MAH

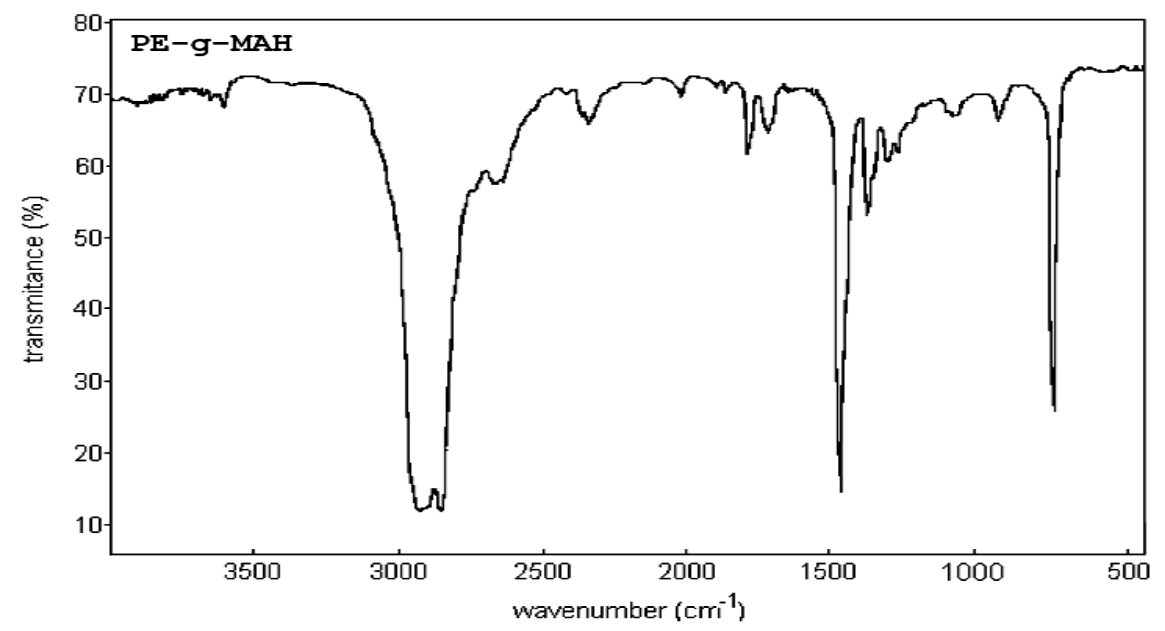

Figure 3. FT-IR Spectrum of PE-g-MAH

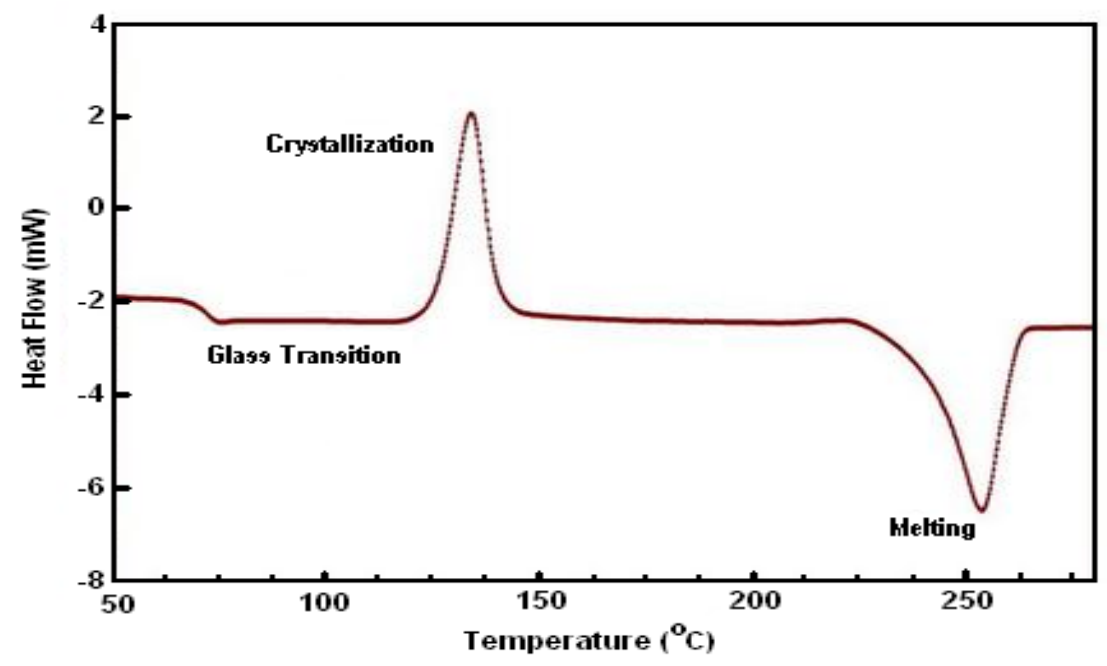

Figure 4. Differential Scanning Calorimetric (DSC) analysis of PE

\subsection{Thermal Analysis}

It is know from the literature that the glass transition temperature $\left(\mathrm{T}_{\mathrm{g}}\right)$ of $\mathrm{PE}$ is about $20^{\circ} \mathrm{C}$ and the melting temperature $\left(\mathrm{T}_{\mathrm{m}}\right) 130^{\circ} \mathrm{C}$. Also the ash ignition temperature is $340^{\circ} \mathrm{C}$ while the self-ignition temperature is $350^{\circ} \mathrm{C}$ in air. In the current study, PE sample was heated in air. The plot in
Figure 4 shows endothermic peaks occur around $138^{\circ} \mathrm{C}$.

Thermal analysis data corresponds to saw dust in air is shown in Figure 5. There is an endothermic peak around $355^{\circ} \mathrm{C}$ representing thermal degradation. There are also two exothermic peaks observed around $328^{\circ} \mathrm{C}$ and $445{ }^{\circ} \mathrm{C}$ resulting from combustion. 


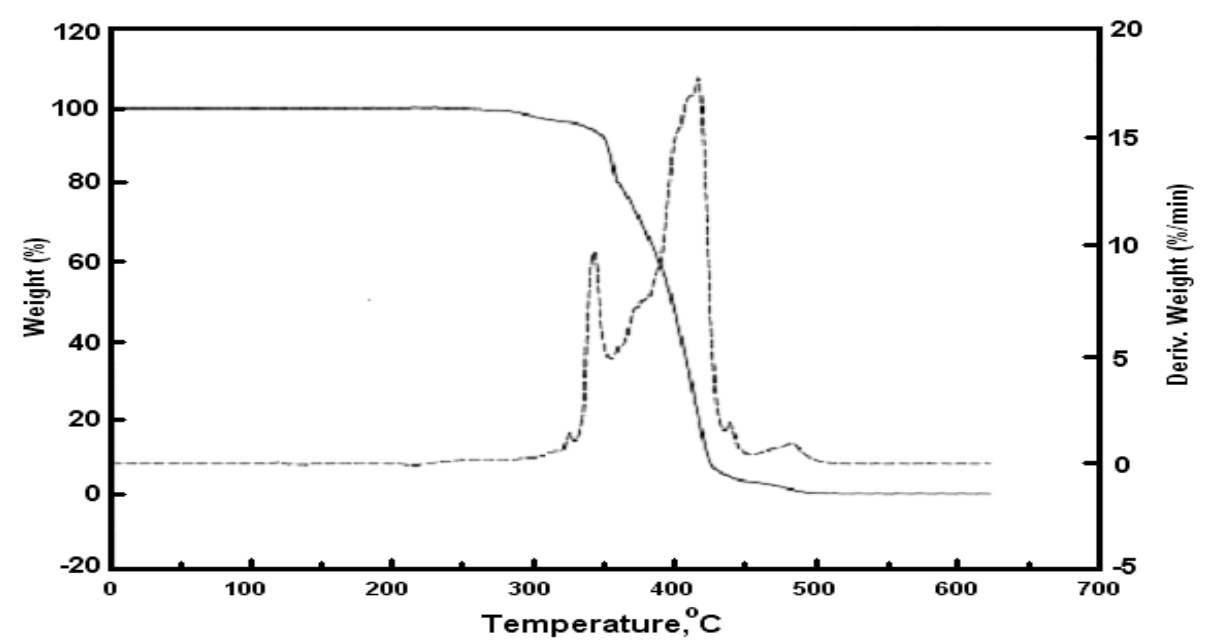

Figure 5. TG-DTG plot of $P E$ in air at heating rate of $10^{\circ} \mathrm{C} / \mathrm{min}$

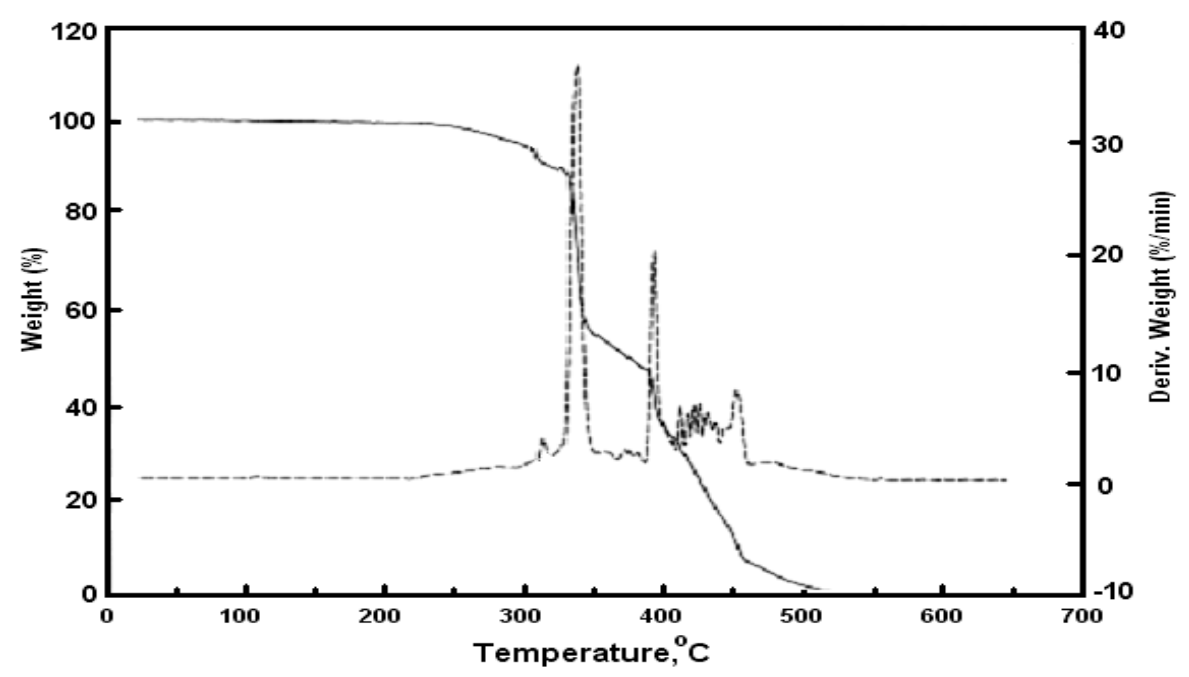

Figure 6. TG-DTG of WPC sample in air at heating rate of $10^{\circ} \mathrm{C} / \mathrm{min}$

Figure 6 shows TG-DTG plots of WPC composed of PE and saw dust where the peak at $315^{\circ} \mathrm{C}$ results mainly from $\mathrm{PE}$ while that at $355^{\circ} \mathrm{C}$ results from both $\mathrm{PE}$ and saw dust. In addition, there is a peak at $435^{\circ} \mathrm{C}$ corresponds to PE only. This means that the addition of saw dust facilitates the oxidation and combustion since wood is more combustible than PE.

\subsection{Tensile Strength}

Samples of WPC used for tensile testing measurements were of the dimensions $\mathrm{W}=19 \mathrm{~mm}, \mathrm{~L}=115$ $\mathrm{mm}$ and $\mathrm{T}=3.5 \mathrm{~mm}$ as shown in Figure 7 Tests were conducted on samples at a speed of $100 \mathrm{~mm} / \mathrm{min}$ were repeated 5 times for each condition to obtain more representative results.

The tensile strength of WPC samples were measured by using of a universal tensile testing machine. Figure 8 shows the relationship between the tensile characteristics and the saw dust content (wt \%) in presence of 5\% of PE- $g$-MAH as coupling agent. WPC samples without PE- $g$-MAH have been also measured to prove the effect of PE-g-MAH on the tensile properties of the WPC samples. The maximum tensile strength of the WPC specimens without PE-g-MAH was $38.02 \mathrm{~N} / \mathrm{mm}^{2}$ and decreased with increasing the saw dust content of the sample up to $45 \mathrm{wt} \%$ leading to decrease of the tensile strength to $34.32 \mathrm{~N} / \mathrm{mm}^{2}$. This means that the addition of saw dust up to $45 \mathrm{wt} \%$ lead to reduction in the tensile strength of $9.7 \%$ in comparison with pure PE. This can be attributed to the incompatibility between the hydrophobic PE and saw dust which contain hydrophilic functionalities. This has been reflected as a decrease in the bonding strength between PE and saw dust.

Also, samples with PE-g-MAH as coupling agent showed tensile strength up to $52.06 \mathrm{~N} / \mathrm{mm}^{2}$ at $45 \mathrm{wt} \%$ of saw dust as shown in Table 2 and represented in Figure 8. It is obvious from that the addition of PE- $g$-MAH significantly increased the tensile strength almost in linear manner. This can be attributed to stronger bonding between PE and saw dust in presence of PE- $g$-MAH as coupling agent which contains both hydrophobic and hydrophilic natures represented by PE chains and maleic anhydride functionality added through grafting. 


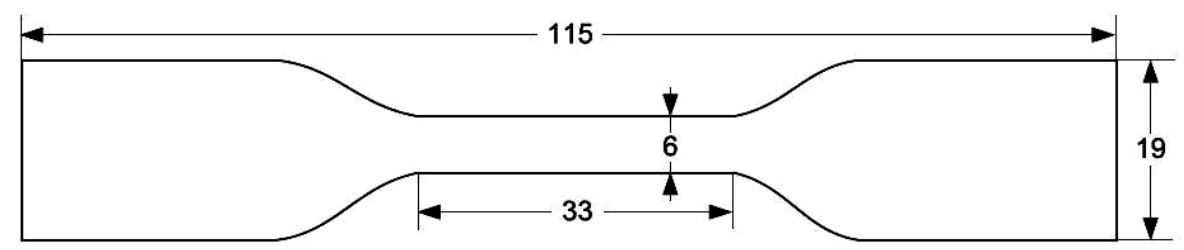

Figure 7. Dimension in mm of WPC test specimens for tensile strength test. Sample thickness for mechanical tests $=3.5 \mathrm{~mm}$

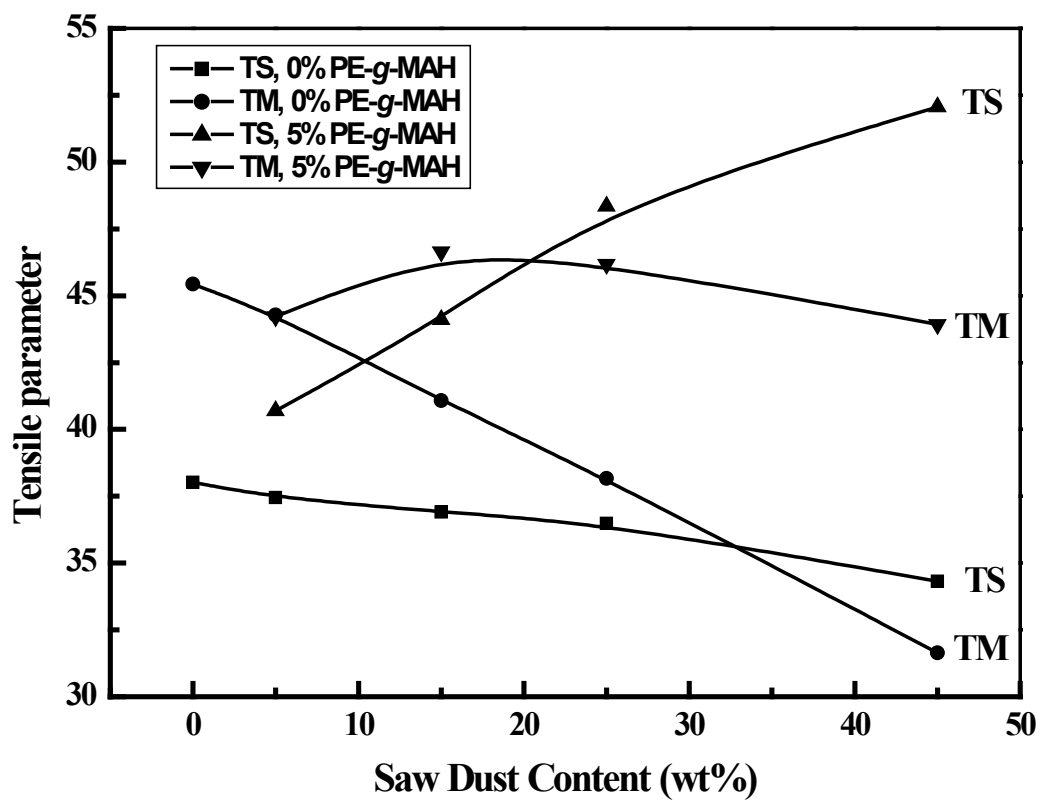

Figure 8. Tensile strength and Tensile Modulus of WPC samples

\subsection{Effect of Saw Dust Content}

Figure 8 shows also that the content of saw dust in WPC samples has remarkable effect decreasing the tensile strength of the samples without PE-g-MAH while the tensile strength increased with the content of saw dust in presence of PE-g-MAH which showed a great impact on the tensile properties of the WPC made of polyethylene and saw dust.

\section{Conclusions and Recommendations}

From the current study, it can be concluded that the chemical modification of PE with Maleic anhydride can lead to promising materials derived from the different polyolefins available in the market. Such modified polyolefins are of better compatibility with natural fibers in the light of their application directions. The tensile strength decreased with increasing saw dust due to the weak bonding with PE. Utilization of PE-g-MAH increased the tensile strength in comparison with pure $\mathrm{PE}$

\section{ACKNOWLEDGEMENTS}

This project was funded by the Saudi Basic International
Corporation (SABIC) through the collaboration with the Deanship of Scientific Research (DSR) at King Abdulaziz University, Jeddah, under Grant \# SP-276/12. The authors, therefore, acknowledge with thank both SABIC and DSR technical and financial support.

\section{REFERENCES}

[1] Weeton, J.W. ; Peters, D.M. and Thomas, K.L., In Engineers' Guide to Composites Materials, American Society for Metals Park, Ohio, U.S.A., pp 1-1 to 8-41 (1987)

[2] Eckert, C., Opportunities for natural fibers in plastic composites. In Proc. Progress in Wood Fiber- Plastic Composites Conference, Toronto, May 25-26 (2000)

[3] Maldas, D.V, Industrial perspective of cellulose in thermoplastic composites. In Handbook of Engineering and Polymeric Materials pp 577-584 (1997)

[4] Yeh, S.-K.; Gupta, R.K., Composites, A39, 1694 (2008)

[5] Rails, T., Wolcott, M.P. and Nassar, J.M., J. Appl. Polym. Sci. $80,546(2001)$

[6] Kamdem, D.P.; Jiang, H.; Cui, W.; Freed, J. and Matuana, 
L.M., Composites A35, 347 (2004)

[7] Kim, J.-P.; Yoon, T.-H.; Mun, S.-P.; Rhee, J.-M. and Lee, J.-S., Biores. Technol. 97, 494 (2006)

[8] Constantinescu, G. and Cazacu, G., Rom. J. Phys., 52(3-4), 375 (2007)

[9] Panthapulakkal, S. and Sain, M., Composites A38, 1445 (2007)

[10] Cui, Y.; Lee, S.; Noruziaan, B.; Cheung, M. and Tao, J., Composites A39, 655 (2008)

[11] Bledzki, A.K.; Mamuna, A.A. and Volk, J., Composites A41, 480 (2010)

[12] Guo, X.; Xiang, D.; Duan, G. and Moua, P., Waste Manag. 30, 4-10 (2010)

[13] Leu, S.Y.; Yang, T.H.; Lo, S.F. and Yang, T.H., Constr. Build. Mater., 29, 120 (2012)

[14] Sojstrom, E., "Wood chemistry fundamentals and applications", Academic Press (1993)
[15] Sundar, S. T.; McDonald, A.G. and Wolcott, M., Proc. Progress in Wood fibre-Plastic Composites Conference, May 10-11. Toronto, Ontario, Canada, (2004)

[16] Rowell, R.M. and Banks, W.B., Water repellency and dimensional stability of wood. USDA Forest Service General Technical Report, FPL 50, FPL Madison Wisconsin, (1985)

[17] Raj, R.G. and Kokta, B.V., Proc. 49 $9^{\text {th }}$ Annual Technical Conference, Montreal, Canada, Society of Plastic Engineers, Brookfield, CT, pp1883-1885, (1991)

[18] Gao, H.; Xie, Y.; Ou, R. and Wang, Q., Composites, A 43, $150(2012)$

[19] Zhong, Y.; Poloso, T.; Hetzer, M., and DeKee, D., Polym. Eng. Sci. 47, 797 (2007).

[20] Li, C.; Zhang, Y. and Zhang, Y., Polym Test, 22, 191 (2003)

[21] Yang, L.; Zhang, F.; Endo, T. and Hirotsu, T., Macromolecules, 36, 4709 (2003)

[22] Sclavons, M.; Franquinet. P.; Carlier, V.; Verfaillie, G.; Fallais, I.; Legras, R.; Laurent, M. and Thyrion, F.C., Polymer, 41, 1989 (2000) 